STOMACH

\title{
Apple polyphenol extracts prevent damage to human gastric epithelial cells in vitro and to rat gastric mucosa in vivo
}

\author{
G Graziani, G D'Argenio, C Tuccillo, C Loguercio, A Ritieni, F Morisco, C Del Vecchio Blanco, \\ V Fogliano, M Romano
}

See end of article for authors' affiliations

.....................

Correspondence to: Dr M Romano

Dipartimento di Internistica Clinica e SperimentaleGastroenterologia, II Policlinico, Edificio 3, II piano, Via Pansini 5, 80131 Napoli, Italy; marco.romano@unina2.it

Revised version received 18 June 2004

Accepted for publication 8 July 2004
Background: Fresh fruit and vegetables exert multiple biological effects on the gastrointestinal mucosa. Aim: To assess whether apple extracts counteract oxidative or indomethacin induced damage to gastric epithelial cells in vitro and to rat gastric mucosa in vivo.

Methods: Apple extracts were obtained from freeze dried apple flesh of the "Annurca" variety. Cell damage was induced by incubating MKN 28 cells with xanthine-xanthine oxidase or indomethacin and quantitated by MTT. In vivo gastric damage was induced by indomethacin $35 \mathrm{mg} / \mathrm{kg}$. Intracellular antioxidant activity was determined using the (2,2' -azinobis (3-ethylbenzothiazolin-6-sulfonate) method. Malondialdehyde intracellular concentration, an index of lipid peroxidation, was determined by high pressure liquid chromatography with fluorometric detection.

Results: (1) Apple extracts decreased xanthine-xanthine oxidase or indomethacin induced injury to gastric epithelial cells by $50 \%$; (2) catechin or chlorogenic acid (the main phenolic components of apple extracts) were equally effective as apple extracts in preventing oxidative injury to gastric cells; and (3) apple extracts (i) caused a fourfold increase in intracellular antioxidant activity, (ii) prevented its decrease induced by xanthine-xanthine oxidase, (iii) counteracted xanthine-xanthine oxidase induced lipid peroxidation, and (iv) decreased indomethacin injury to the rat gastric mucosa by $40 \%$.

Conclusions: Apple extracts prevent exogenous damage to human gastric epithelial cells in vitro and to the rat gastric mucosa in vivo. This effect seems to be associated with the antioxidant activity of apple phenolic compounds. A diet rich in apple antioxidants might exert a beneficial effect in the prevention of gastric diseases related to generation of reactive oxygen species.
I: $\mathrm{n}$ the stomach there is massive production of reactive oxygen species (ROS), their concentration being 1000-fold higher than in other tissues or plasma. ${ }^{1}$ Generation of ROS contributes to exogenous injury to the gastric mucosa in vitro and in vivo. $^{2-4}$ Moreover, ROS play a major role in the multistep process leading to the development of gastric adenocarcinoma. $^{5}$

Fresh fruit and vegetables have been reported to exert multiple biological effects on the mucosa of the gastrointestinal tract due to their antioxidants content. ${ }^{6}$ In particular, a diet rich in vegetable is associated with a lower incidence of gastric tumours. ${ }^{78}$ Also, Eberhardt and colleagues 9 reported strong inhibition of tumour cell proliferation in vitro by apple extract, and suggested that the antiproliferative effect could be due to the presence of phytochemicals (phenolic acids and flavonoids) other than ascorbic acid. Therefore, dietary antioxidants play a crucial role in the maintenance of gastric homeostasis by counteracting the potentially mucosal damaging effects exerted by ROS.

It is well known that dietary antioxidants scavenge oxygen and nitrogen free radicals, breaking lipid chain peroxidation reactions. Phenolic compounds are one of the major classes of dietary antioxidants and, in particular, apple phenolic compounds represent $22 \%$ of the total amount of phenolic compounds present in the diet of US consumers. ${ }^{10}$ Apart from their action as radical scavengers, phenolic compounds also have several indirect effects; they can inhibit lipoxygenase, ${ }^{11}$ reduce platelet aggregation, ${ }^{12}$ and reduce the bioavailability of food carcinogens. ${ }^{13}$ Certain flavonoids or compounds with flavonoid-like properties have antiulcer activity and prevent gastric mucosal lesions brought about by a number of ulcerogens. ${ }^{14-16}$ Whether apple phenolic compounds have a protective effect against oxidative stress related injury to gastric epithelial cells is unknown.

Therefore, this study was designed: (1) to evaluate whether apple polyphenol extracts (APE) prevent ROS induced injury to human gastric epithelial cells in vitro, under conditions independent of gastric secretion or systemic factors, including blood flow; and (2) to identify the mechanisms responsible for any such protective effect. We decided to use cultured gastric epithelial cells as an experimental model, the gastric epithelial lining being the first site where the interaction between endogenously generated ROS and dietary antioxidants takes place in vivo. Gastric mucosa injury brought about by non-steroidal anti-inflammatory drugs (NSAIDs), and in particular by indomethacin or aspirin, is in part mediated by generation of ROS. ${ }^{3}{ }^{17}$ We have previously studied the effect of indomethacin and aspirin on cell vacuolation induced by Helicobacter pylori in MKN 28 cells and found comparable results. ${ }^{18}$ We therefore investigated whether APE prevented NSAID induced injury both in vitro and in the rat gastric mucosa in vivo, and chose indomethacin as an example of NSAID injury.

Abbreviations: ROS, reactive oxygen species; NSAIDs, non-steroidal anti-inflammatory drugs; $\mathrm{APE}$, apple polyphenol extracts; $\mathrm{BHT}$, butylated hydroxytoluol; HPLC, high pressure liquid chromatography; CAT, catechin; CA, chlorogenic acid; ECAT, epicatechin; X, xanthine; $X O$, xanthine oxidase; MTT, 3-(4,5-dimethylthiazol-2-yl)-2,5-diphenyl tetrazoliumbromide; LDH, lactate dehydrogenase; MDA, malondialdehyde 


\section{MATERIAL AND METHODS}

\section{Preparation of apple extract}

Freeze dried apple flesh of the "Annurca" variety ( 1 g) was extracted with $5 \mathrm{ml}$ of methanol containing $1 \%$ butylated hydroxytoluol (BHT). Three successive extractions were carried out at $4^{\circ} \mathrm{C}$ for one hour in the dark. Methanol extracts were pooled and filtered on Millipore Millex-GN $0.2 \mu \mathrm{m}$ before analysis by high pressure liquid chromatography (HPLC) and mass spectrometry. The same extract was assayed for antioxidant activity and for measuring the protective effects on cultured gastric cells.

\section{Identification and quantitation of phenolic compounds in apple flesh extracts}

Phenolic compounds were separated by HPLC (ShimadzuCLASS M10) configured with LC-10AD pumps, SPD-M10A diode array detector, and Rheodyne injector. The mobile phase (flow rate $1 \mathrm{ml} /$ minutes) consisted of acidified water (0.01 M phosphoric acid, solvent A) and methanol (solvent B). Separation was obtained by the following gradient: at 0 minute $5 \% \mathrm{~B}$; at 10 minutes $50 \% \mathrm{~B}$; at 20 minutes $70 \% \mathrm{~B}$; at 25 minutes $80 \% \mathrm{~B}$; at 30 minutes $100 \% \mathrm{~B}$; at 35 minutes $50 \% \mathrm{~B}$; and at 40 minutes $5 \%$ B. Phenolic compounds determined were $(+)$-catechin (CAT), chlorogenic acid (CA), (-)-epicatechin (ECAT), caffeic acid, rutin, and phloridizin. Analytical separations were performed on a Luna reversed phase $\mathrm{C}_{18}(5 \mu \mathrm{m})$ column $(25 \times 4.6 \mathrm{~mm}$ ID). All solvents were for HPLC grade and degassed with helium at room temperature before use. CAT, ECAT, phloridizin, and rutin were detected at $280 \mathrm{~nm}$ and CA and caffeic acid at $325 \mathrm{~nm}$. Phenolic compounds were expressed in $\mathrm{mg} / \mathrm{l00} \mathrm{g}$ of fresh weight. Identification of phenolic compounds present in APE was performed by HPLC-ESI-MS analysis, as described elsewhere. ${ }^{19}$ To obtain the molar concentration of APE, the sum of all peaks present in the chromatogram were considered and quantified using the calibration curve of CAT. Therefore, APE amount was expressed in CAT equivalents.

\section{Cell culture}

MKN 28 cells were derived from a human well differentiated gastric tubular adenocarcinoma and showed gastric-type differentiation. ${ }^{20}$ Cells were grown as monolayers in Dulbecco's modified Eagle's medium supplemented with $10 \%$ fetal calf serum and $1 \%$ antibiotic-antimycotic solution (Life Technologies Inc., Gaithersburg, Maryland, USA) at $37^{\circ} \mathrm{C}$ in a humidified atmosphere of $5 \% \mathrm{CO}_{2}$ in air. Cytotoxicity experiments were conducted using serum free medium (no added antibiotic-antimycotic solution).

\section{Induction of oxidative stress}

Oxidative stress was induced by incubating MKN 28 cells with xanthine oxidase ( $\mathrm{XO} 10-100 \mathrm{mU} / \mathrm{ml})$ in the presence of its substrate xanthine (X $1 \mathrm{mM}$ ) for periods of up to three hours. Exposure of gastric cells in culture to X-XO causes significant cell injury and this has been demonstrated to be due to generation of ROS and in particular of $\mathrm{OH}$ produced from $\mathrm{H}_{2} \mathrm{O}_{2}$ by the iron catalysed Fenton reaction. ${ }^{21}{ }^{22}$

\section{Cell viability}

Cell viability was determined by the MTT (3-(4,5dimethylthiazol-2-yl)-2,5-diphenyl tetrazoliumbromide) assay. Briefly, $10 \mu \mathrm{l}$ of MTT ( $5 \mathrm{mg} / \mathrm{ml}$ saline) were added to each well, and samples were incubated for 90 minutes at $37^{\circ} \mathrm{C}$ and centrifuged ( $300 \mathrm{~g}$ for five minutes). After aspiration of supernatant, cells were lysed and solubilised by addition of $100 \mu \mathrm{l}$ of $0.04 \mathrm{~N} \mathrm{HCl}$ containing isopropanol. Absorbance of each sample was analysed at $590 \mathrm{~nm}$ using Microplate Reader. Cell viability (\%) was calculated by dividing the absorbance of samples obtained from cells incubated with test drugs by the absorbance of samples obtained from cells incubated with tissue culture medium only (control) and multiplying this ratio by 100 . Data are presented as the mean (SD) of three experiments run in duplicate. In addition, cells were assayed for release of the cytoplasmic enzyme lactate dehydrogenase (LDH) as a marker of cytotoxicity, as previously described by Hiraishi and colleagues. ${ }^{23}$ Because the presence of oxidants may interfere with the measurement of LDH released, ${ }^{24}$ after incubation with $\mathrm{X}$ and $\mathrm{XO}$ cells were gently washed twice and further incubated in serum free medium for five hours under culture conditions. A sample of the supernatant ( $100 \mu \mathrm{l})$ was collected by centrifugation at 10000 revolutions/min in a Beckman microcentrifuge for one minute and the supernatant was stored at $-20^{\circ} \mathrm{C}$ until assay. $\mathrm{LDH}$ was measured spectrophotometrically at $340 \mathrm{~nm}$ using a Sigma assay kit. Total LDH content was determined in wells incubated in $0.2 \%$ Triton X-100 and the mean was taken as total LDH. Specific LDH release was expressed as

\section{$(\mathrm{A}-\mathrm{B}) /(\mathrm{C}-\mathrm{B}) \times 100$}

where A represents $\mathrm{LDH}$ released after exposure to $\mathrm{X}-\mathrm{XO}, \mathrm{B}$ represents spontaneous $\mathrm{LDH}$ release (that is, $\mathrm{LDH}$ release from control untreated cells), and $\mathrm{C}$ represents total $\mathrm{LDH}$ release. Spontaneous LDH release was approximately $10 \%$ of total LDH after five hours of incubation.

Quantitation of phenolic compounds in MKN 28 cells Pellets (600 000 cells $/ \mathrm{ml}$ ) washed extensively with phosphate buffered saline were extracted using $300 \mu \mathrm{l}$ of methanol $\left(0.01 \%\right.$ BHT) in an ultrasonic bath for 30 minutes at $4^{\circ} \mathrm{C}$. The final extract was centrifuged at $13000 \mathrm{~g}$ and the supernatant was used for HPLC analysis under the same conditions as described for apple flesh extract. In this case, phenolic compounds were expressed as ng/ $10^{6}$ cells.

\section{Measurement of antioxidant activity}

Determination of antioxidant activity of the methanol extracts was performed by the ABTS method, as described by Pellegrini and colleagues, ${ }^{25}$ using the same extracts prepared for HPLC analysis. Determination of total antioxidant activity is an indirect measure of oxidative stress and can be applied to biological substances as an index of the oxidative stress/antioxidant balance. In brief, $100 \mu \mathrm{l}$ of a 1:80 dilution of extract dissolved in $\mathrm{CH}_{3} \mathrm{OH}$ were tested. Antioxidant activity was expressed as $\mu \mathrm{M}$ trolox/l00 $\mathrm{g}$ of fresh weight. Antioxidant activity was also measured on cellular pellets after each treatment; in this case antioxidant activity was expressed as $\mu \mathrm{M}$ trolox $/ 10^{6}$ cells.

Table 1 Quali-quantitative analysis of the main phenolic compounds in apple flesh (Annurca variety)

\begin{tabular}{lc}
\hline Polyphenol compound & $\begin{array}{l}\text { Concentration } \\
\text { (mg/100 g of apple flesh) }\end{array}$ \\
\hline Chlorogenic acid & $9.06(1.09)$ \\
Caffeic acid & $0.18(0.10)$ \\
Catechin & $11.93(1.23)$ \\
Epicatechin & $6.34(1.85)$ \\
Rutin & $0.15(0.03)$ \\
Phloridizin & $1.09(0.31)$ \\
\hline
\end{tabular}

Mean (SD) from three separate experiments. Analysis was carried out with high pressure liquid chromatography and peaks were monitored at $280 \mathrm{~nm}$ (catechin, epicatechin, rutin, and phloridizin) and at $325 \mathrm{~nm}$ (chlorogenic acid and caffeic acid). 


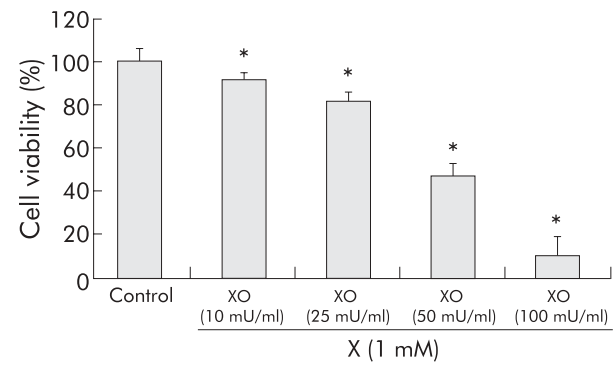

Figure 1 Xanthine-xanthine oxidase $(X-X O)$ dose dependently injured MKN 28 cells. Cells were incubated for two hours with XO (10$100 \mathrm{mU} / \mathrm{ml}$ ) in the presence of $X 1 \mathrm{mM}$ or serum free medium (control). Mean (SD) from three separate experiments run in duplicate. ${ }^{*} p<0.05$ versus control.

\section{Determination of lipid peroxidation}

Lipid peroxidation was determined by measuring cellular malondialdehyde (MDA). Determination of cellular MDA was performed by HPLC with fluorometric detection, according to the method of Bergamo and colleagues. ${ }^{26}$ Cellular pellets were extracted with $250 \mu \mathrm{l}$ of Milli-Q water in an ultrasonic bath for 30 minutes after addition of $250 \mu \mathrm{l}$ of cold $10 \%$ TCA. Samples were vigorously mixed (three minutes) and centrifuged (five minutes, $10000 \mathrm{~g}$ ). The supernatant was added to $700 \mu \mathrm{l}$ of thiobarbituric acid prepared using thiobarbituric acid in $2 \mathrm{M}$ acetate buffer at $\mathrm{pH} \mathrm{3,} \mathrm{degassing}$ by a vacuum pump (five minutes), and flushing the final solution with nitrogen for 10 minutes. The mixtures were degassed and then incubated for 30 minutes at $90^{\circ} \mathrm{C}$. At the end of the incubation period, samples were cooled, centrifuged (five minutes, $10000 \mathrm{~g}$ ) to remove particulate material and, finally, sample aliquots $(20 \mu \mathrm{l})$ were analysed by HPLC. Quantitation of MDA was obtained from a calibration curve constructed by injecting increasing amounts of standard MDA. MDA concentration was expressed as $\mu \mathrm{g} / 10^{6}$ cells.

\section{Induction of gastric mucosal damage}

Male Wistar rats weighing 180-220 g were randomly divided into four groups of eight rats each and housed in wire bottomed cages with free access to water and standard laboratory rat food. Animals were obtained from Morini (Italy) and maintained under controlled temperature conditions of $22 \pm 1{ }^{\circ} \mathrm{C}$ with a 12 hour light-dark cycle. Rats were fasted 20 hours before the experiments and allowed free

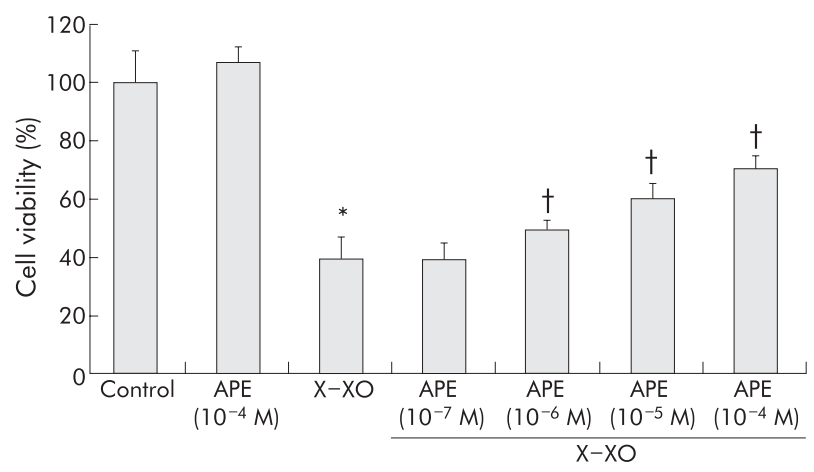

Figure 2 Apple polyphenol extracts (APE) dose dependently prevented xanthine-xanthine oxidase (X-XO) induced damage to MKN 28 cells. MKN 28 cells were incubated with APE $10^{-7}$ to $10^{-4} \mathrm{M}$ or with serum free medium (control) for three hours and then, after washing, with $X$ $(1 \mathrm{mM})-\mathrm{XO}(50 \mathrm{mU} / \mathrm{ml})$ or serum free medium for two hours. Mean (SD) from three separate experiments run in duplicate. ${ }^{*} \mathrm{p}<0.05$ versus control; $\uparrow p<0.05$ versus $X-X O$. access to water. The experiments were approved by the university ethics committee. Sixteen animals (eight per each study group) were treated with APE $10^{-4} \mathrm{M}$ or vehicle (control) for 10 days, administered as drinking beverage, and then given indomethacin $35 \mathrm{mg} / \mathrm{kg}$ subcutaneously. Another group of 16 rats (eight per each study group) received APE $10^{-4} \mathrm{M}(2 \mathrm{ml})$ or vehicle (control) by gavage one hour before indomethacin. Animals were sacrificed four hours after indomethacin administration under anaesthesia. The stomachs were removed and opened along the greater curvature, rinsed in cold saline, and inspected for macroscopic damage. Then, the area of haemorrhagic lesions developed in the corpus mucosa was measured under a dissecting microscope with a square grid (x10), summed per stomach, and used as a lesion score. ${ }^{27}$ Samples for histology were taken. The investigator measuring the lesions (GD) was unaware of the treatments given to the animals.

\section{Histology}

Samples for light microscopy were excised from the gastric glandular epithelium at a region located $2 \mathrm{~mm}$ below the limiting ridge that separates the forestomach from the glandular epithelium along the greater curvature of the stomach. Blocks were removed at right angles to the long axis of the stomach. A light microscopic sample measuring $\sim 1 \mathrm{~mm} \times 10 \mathrm{~mm}$ was removed. The same procedure was performed on a second sample that was removed at $\sim 0.5 \mathrm{~cm}$ distal to the first sampling area. ${ }^{28}$ Thus two light microscopic blocks were removed, fixed in formalin, and processed for each tissue. Using haematoxylin and eosin stained paraffin embedded sections of tissue, the extent of mucosal injury was quantified. Slides were examined in a blinded fashion by coding them in such a way so that the examiner was unfamiliar with the experimental protocol. Only after the examination was complete were they decoded. Using a graded micrometer eyepiece, within each tissue block pair from each stomach the overall length of tissue section was measured and the corresponding percentage of length of mucosal surface injured was determined. The mucosa was considered injured if one or more of the following criteria were present: discontinuous surface, dilated gland, haemorrhage, or damage to superficial cells.

\section{Statistical analysis}

Data are expressed as mean (SD). Significance of differences was assessed by one way analysis of variance (ANOVA) and (when the $F$ value was significant) by the Tukey-Krammer test for multiple comparisons or by the Student's $t$ test for comparison between two means. ${ }^{29}$ Differences were considered to be significantly different if $\mathrm{p}<0.05$.

\section{RESULTS \\ Identification and concentration of apple phenolic compounds}

Apple phenolic compounds present in flesh extract and their concentrations are listed in table 1. Chlorogenic acid was present in the highest concentration, followed by CAT, ECAT, and phloridizin. This is in agreement with previous data reported in the literature. ${ }^{30}{ }^{31}$ Caffeic acid and other phenolic acid were only present at low concentrations.

\section{Effect of oxidative stress on MKN 28 cell viability}

We first sought to investigate whether MKN 28 cells were susceptible to oxidative stress induced damage. Oxidative stress was induced by incubating epithelial cell monolayers with $\mathrm{XO}(10-100 \mathrm{mU} / \mathrm{ml})$ in the presence of its substrate $\mathrm{X}$ $(1 \mathrm{mM})$ for periods of up to three hours. ${ }^{21} 22$ Two hour incubation with $\mathrm{X}(1 \mathrm{mM})$ and $\mathrm{XO}(10-100 \mathrm{mU} / \mathrm{ml})$ caused a dose dependent and significant $(\mathrm{p}<0.05)$ reduction in cell viability, as assessed by the MTT assay (fig 1). For the 
Table 2 Time course of apple polyphenol extracts (APE) protection against xanthinexanthine oxidase $(\mathrm{X}-\mathrm{XO})$ induced cell damage

\begin{tabular}{llllll}
\hline \multicolumn{5}{l}{ Cell viability (\%) } \\
\cline { 2 - 6 } & $\mathbf{1 ~ h}$ & $\mathbf{3 ~ h}$ & $\mathbf{6 ~ h}$ & $\mathbf{1 2 ~ h}$ & $\mathbf{2 0 ~ h}$ \\
\hline Control & 100 & 100 & 100 & 100 & 100 \\
X-XO & $38.5(1.8)^{*}$ & $39.9(2.6)^{*}$ & $37.5(2.4)^{*}$ & $37.9(1.8)^{*}$ & $41.4(1.7)^{*}$ \\
APE & $99(1.0)$ & $100(2.9)$ & $102(3.6)$ & $96(2.7)$ & $97(3.5)$ \\
APE, X-XO & $35.2(2.5)$ & $70.2(1.5) \dagger$ & $50(2.5) \dagger$ & $48.8(1.2) \dagger$ & $40.4(0.9)$ \\
\hline
\end{tabular}

Mean (SD) from three separate experiments run in duplicate.

Control, cells treated with serum free medium for 1-20 hours and then with vehicle for $X-X O$ for two hours. $\mathrm{X}-\mathrm{XO}$, cells treated with serum free medium for $1-20$ hours and then with $\mathrm{X}(1 \mathrm{mM})+\mathrm{XO}(50 \mathrm{mU} / \mathrm{ml})$ for two hours.

APE, cells treated with APE $\left(10^{-4} M\right)$ for $1-20$ hours and then with vehicle for $X$-XO for two hours.

APE, $X-X O$, cells treated with APE $\left(10^{-4} \mathrm{M}\right)$ for $1-20$ hours and then with $X(1 \mathrm{mM})+X O(50 \mathrm{mU} / \mathrm{ml})$ for two hours.

${ }^{*} \mathrm{p}<0.05$ versus control; $\mathrm{tp}<0.05$ versus $\mathrm{X}-\mathrm{XO}$

following experiments a concentration of $\mathrm{X}(1 \mathrm{mM})$ and $\mathrm{XO}$ $(50 \mathrm{mU} / \mathrm{ml})$ were selected which led to a decrease in cell viability close to $60 \%$ (fig 1).We obtained comparable results using the LDH assay (data not shown) and therefore in the following experiments cell viability was determined only by the MTT assay.

\section{Effect of APE on X-XO induced cell damage}

We then examined whether pretreatment with APE counteracted X-XO induced injury to MKN 28 cells. APE, used at concentrations which did not alter cell viability, prevented $\mathrm{X}-\mathrm{XO}$ induced cell injury in a dose dependent manner (fig 2). In particular, pretreatment with APE $10^{-4} \mathrm{M}$ three hours before $\mathrm{X}-\mathrm{XO}$ caused a significant increase in cell viability compared with that of cells exposed to $\mathrm{X}-\mathrm{XO}$ only (that is, $70 \% \vee 40 \%$, respectively; $\mathrm{p}<0.05)$. Moreover, the time course of the APE $10^{-4} \mathrm{M}$ protective effect showed maximal protection at three hours which declined over time and became almost negligible at 20 hours (table 2).

Effect of APE components on X-XO induced cell injury We tested whether CAT or CA, the major phenolic components of APE, prevented X-XO induced injury to MKN 28 cells. Three hour pretreatment with CAT $10^{-4} \mathrm{M}$ or CA $10^{-4} \mathrm{M}$ did not affect cell viability per se but had a protective effect against X-XO injury comparable with that obtained with APE $10^{-4} \mathrm{M}$ (fig 3). In particular, CA seemed more effective than CAT (70\% $v 60 \%$ cell viability, respectively)

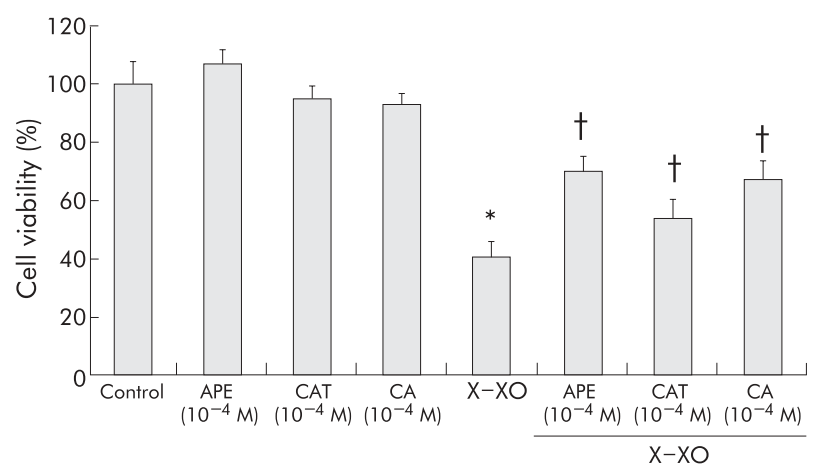

Figure 3 Protective effect of apple polyphenol extracts (APE), catechin (CAT), or chlorogenic acid (CA) against xanthine-xanthine oxidase (X-XO) induced cell injury. Cells were incubated with serum free medium (control) or with APE $\left(10^{-4} \mathrm{M}\right), \mathrm{CAT}\left(10^{-4} \mathrm{M}\right)$, or $\mathrm{CA}\left(10^{-4} \mathrm{M}\right)$ for three hours and then, after washing, with $X(1 \mathrm{mM})-X O(50 \mathrm{mU} / \mathrm{ml})$ or serum free medium (control) for two hours. Mean (SD) from three separate experiments run in duplicate. ${ }^{*} \mathrm{p}<0.05$ versus control; $\mathrm{tp}<0.05$ versus $\mathrm{X}-\mathrm{XO}$.
Table 3 Effect of apple polyphenol extracts (APE) or APE followed by xanthine-xanthine oxidase (X-XO) on endocellular concentrations of the main apple phenolic compounds

\begin{tabular}{|c|c|c|}
\hline & APE $\left(10^{-4} M\right)$ & $\begin{array}{l}\text { APE }\left(10^{-4} \mathrm{M}\right) \\
X(1 \mathrm{mM})- \\
\text { XO }(50 \mathrm{mU} / \mathrm{ml})\end{array}$ \\
\hline $\begin{array}{l}\text { Catechin (ng/10 } / 0^{6} \text { cells) } \\
\text { Epicatechin (ng/10 } / 10^{6} \text { cells) } \\
\text { Chlorogenic acid (ng/10 cells) }\end{array}$ & $\begin{array}{l}3.196(0.098) \\
0.764(0.002) \\
5.62(0.867)\end{array}$ & $\begin{array}{l}0.376(0.004) \\
\text { nd } \\
1.97(0.078)\end{array}$ \\
\hline \multicolumn{3}{|c|}{$\begin{array}{l}\text { Cells were incubated with } A P E\left(10^{-4} \mathrm{M}\right) \text { for three hours and then with } \\
\text { serum free medium or } \mathrm{X}(1 \mathrm{mM})-\mathrm{XO}(50 \mathrm{mU} / \mathrm{ml}) \text { for two hours. } \\
\text { Mean (SD) from three separate experiments run in duplicate. } \\
\text { nd, not detectable. }\end{array}$} \\
\hline
\end{tabular}

even though this was not statistically different. Therefore, pure CAT or CA are equally effective as APE in preventing $\mathrm{X}-\mathrm{XO}$ induced injury to MKN 28 cells.

\section{Effect of X-XO or APE on phenolic compound concentration in MKN 28 cells}

In order to elucidate the mechanism of the protective effect exerted by APE, we determined whether apple phenolic compounds were able to enter MKN 28 cells by measuring the intracellular concentration of the major apple phenolic compounds (that is, CAT, CA, and ECAT) following incubation with APE $10^{-4} \mathrm{M}$. CAT, CA, or ECAT were undetectable in untreated (control) MKN 28 cells (data not shown). Incubation with APE resulted in a marked increase in intracellular concentration of CAT, CA, and ECAT (table 2), thus indicating that these compounds are able to penetrate cell membranes. Exposure of cells to X-XO for two hours following pretreatment with APE caused a significant reduction in APE induced increase in CAT, CA, or ECAT concentration (table 3 ). This suggests that apple phenolic compounds are consumed to counteract the oxidative stress induced by X-XO generated ROS. Another possibility is that as cells are becoming less viable, these compounds may be extruded due to increased cellular permeability. To rule out this, we determined phenolic compound concentrations in the culture medium of cells pretreated with APE and then exposed to $\mathrm{X}-\mathrm{X} 0$ or serum free medium (control) and found no significant difference (data not shown).

\section{Effect of APE or X-XO on intracellular antioxidant activity in MKN 28 cells}

To further elucidate the mechanism of the protective effect of APE against oxidative stress induced cell injury, we first investigated whether $\mathrm{X}-\mathrm{XO}$ decreased intracellular 

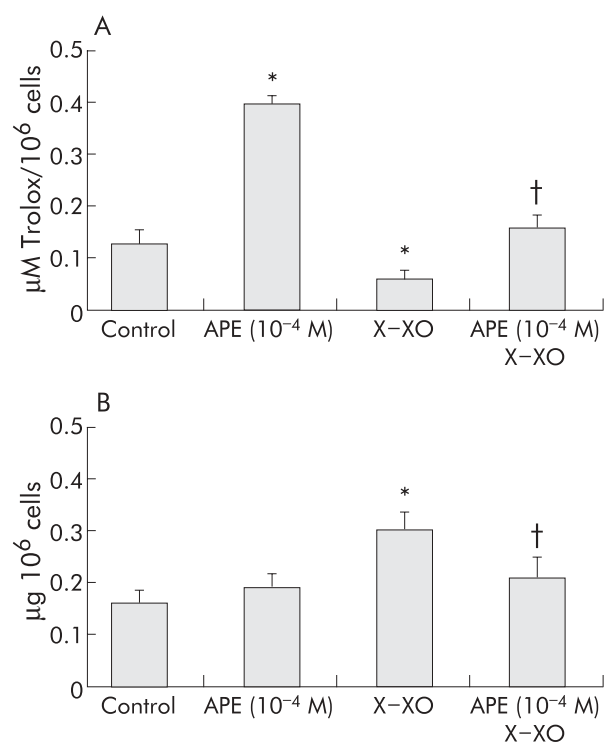

Figure 4 Effects of apple polyphenol extracts (APE) on total antioxidant intracellular activity and on lipid peroxidation in MKN 28 cells. (A) APE prevented xanthine-xanthine oxidase $(X-X O)$ induced decrease in total antioxidant intracellular activity in MKN 28 cells. Cells were treated with serum free medium (control) or APE $\left(10^{-4} \mathrm{M}\right)$ for three hours and then with serum free medium or $X(1 \mathrm{mM})-X O(50 \mathrm{mU} / \mathrm{ml})$ for two hours. Mean (SD) of three separate experiments run in duplicate. ${ }^{*} p<0.05$ versus control; $\uparrow p<0.05$ versus $X-X O$. (B) APE prevented $X-X O$ induced increase in cellular MDA in MKN 28 cells. Cells were treated with serum free medium (control) or APE $\left(10^{-4} \mathrm{M}\right)$ for three hours and then with serum free medium or X $(1 \mathrm{mM})-X O(50 \mathrm{mU} / \mathrm{ml})$ for two hours. Mean (SD) from three separate experiments run in duplicate. ${ }^{*} p<0.05$ versus control; $\uparrow p<0.05$ versus $X-X O$.

antioxidant activity in MKN 28 cells and whether APE were able to counteract any such effect. APE $10^{-4} \mathrm{M}$ caused an approximate 4.0 -fold increase in intracellular antioxidant activity whereas $\mathrm{X}$-XO caused an approximate 2.0-fold decrease in intracellular antioxidant activity compared with untreated (control) cells (fig 4A). APE $10^{-4} \mathrm{M}$ completely and significantly counteracted the $\mathrm{X}-\mathrm{XO}$ induced decrease in intracellular antioxidant activity (fig 4A). A similar increase in intracellular antioxidant activity was also obtained with pure CAT or CA (data not shown). This suggests that the protective effect exerted by APE is at least in part associated with its antioxidant activity.

\section{Effect of APE on X-XO induced lipid peroxidation in MKN 28 cells}

ROS induced cell damage is associated with cell membrane disruption due to lipid peroxidation. We therefore hypothesised that APE might prevent lipid peroxidation brought about by $\mathrm{X}-\mathrm{XO}$ generated ROS. To address this issue, we evaluated whether X-XO increased cellular MDA, a marker of lipid peroxidation, and whether APE pretreatment was able to counteract any such effect. Exposure of MKN 28 cells to $\mathrm{X}$-XO caused a twofold increase in cellular MDA concentration compared with control untreated cells (fig 4B). Moreover, pretreatment with APE $10^{-4} \mathrm{M}$ significantly prevented $\mathrm{X}-\mathrm{XO}$ induced increase in cellular MDA. This suggests that the protective effect of APE is partially due to inhibition of ROS induced lipid peroxidation.

Effect of APE on indomethacin induced gastric mucosa
cell injury
NSAID induced injury to the gastric mucosa is partly attributable to generation of ROS. ${ }^{317}$ We therefore evaluated

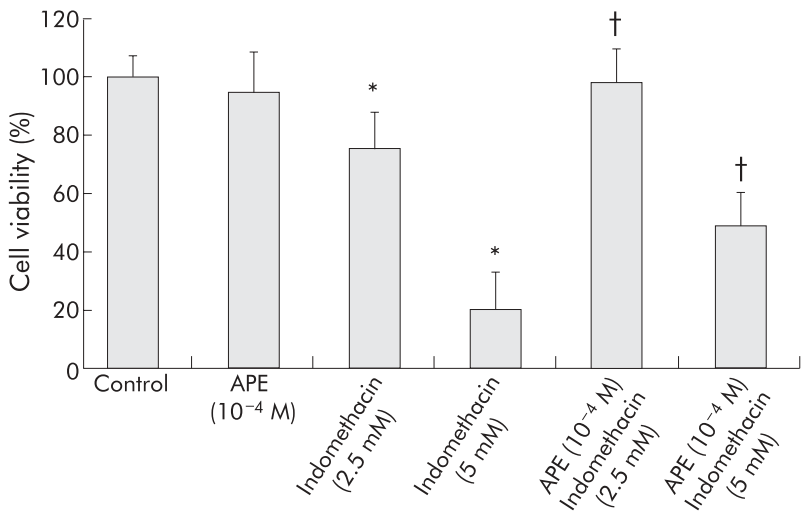

Figure 5 Apple polyphenol extracts (APE) prevent indomethacin induced injury to MKN 28 cells. Cells were treated with serum free medium (control) or APE $\left(10^{-4} \mathrm{M}\right)$ for three hours and then with serum free medium or indomethacin $2.5 \mathrm{mM}$ or $5 \mathrm{mM}$ for three hours. Mean (SD) from three separate experiments run in duplicate. ${ }^{*} p<0.05$ versus control; $\mathrm{tp}<0.05$ versus indomethacin.

whether APE protected gastric cells in culture against damage caused by indomethacin. Indomethacin $2.5 \mathrm{mM}$ or $5 \mathrm{mM}$ caused dose dependent damage to MKN 28 cells, decreasing cell viability to $80 \%$ and $20 \%$, respectively (fig 5 ). Pretreatment with APE $10^{-4} \mathrm{M}$ significantly prevented indomethacin induced injury (fig 5). In particular, APE completely prevented the damaging effect exerted by indomethacin $2.5 \mathrm{mM}$ and significantly decreased the extent of cell injury induced by indomethacin $5 \mathrm{mM}$ (fig 5), increasing cell viability from $20 \%$ to $50 \%$.

\section{Effect of APE on indomethacin induced injury in rats}

Our in vitro experiments suggest that the protective effect of APE is at least in part independent of vascular, hormonal, and neural factors. We then sought to investigate whether APE exerted a similar protective effect in vivo. Indomethacin ( $35 \mathrm{mg} / \mathrm{kg}$ subcutaneously) induced the appearance of multiple visible gastric erosions, ranging from 2 to $10 \mathrm{~mm}$ in length and about $1 \mathrm{~mm}$ in width (fig 6A). APE $10^{-4} \mathrm{M}$ in drinking water for 10 days prior to indomethacin prevented macroscopic injury to the rat glandular stomach (fig 6B). Figure 6C-E shows representative photomicrographs that display the protective effect of APE on indomethacin induced injury. The typical appearance of the normal gastric mucosa is shown in fig 6C. Indomethacin extensively damaged the superficial epithelium and caused necrosis in the region of the gastric glands (fig $6 \mathrm{D}$ ). In contrast, APE treatment partially prevented microscopic injury caused by indomethacin to the rat stomach decreasing the extent of damage to the superficial epithelium and to the glandular area (fig 6E). Quantitatively, APE pretreatment caused an approximate $45 \%$ decrease in the extent of macroscopic injury compared with control untreated rats $(\mathrm{p}<0.05$, fig $7 \mathrm{~A})$ and reduced the extent of microscopic injury by approximately $40 \%(\mathrm{p}<0.05$, fig 7B). Comparable results, both at the macroscopic and histological level, were obtained in rats treated with APE $10^{-4} \mathrm{M}$ given intragastrically one hour prior to indomethacin injection (data not shown).

\section{DISCUSSION}

Several studies indicate that naturally occurring antioxidants exert protective biochemical effects in a number of biological experimental systems. In particular, phenolic antioxidants, which are widely distributed in vegetable foods, are considered to play an important role in the prevention of oxidative damage in living systems. ${ }^{32}$ Because generation of 

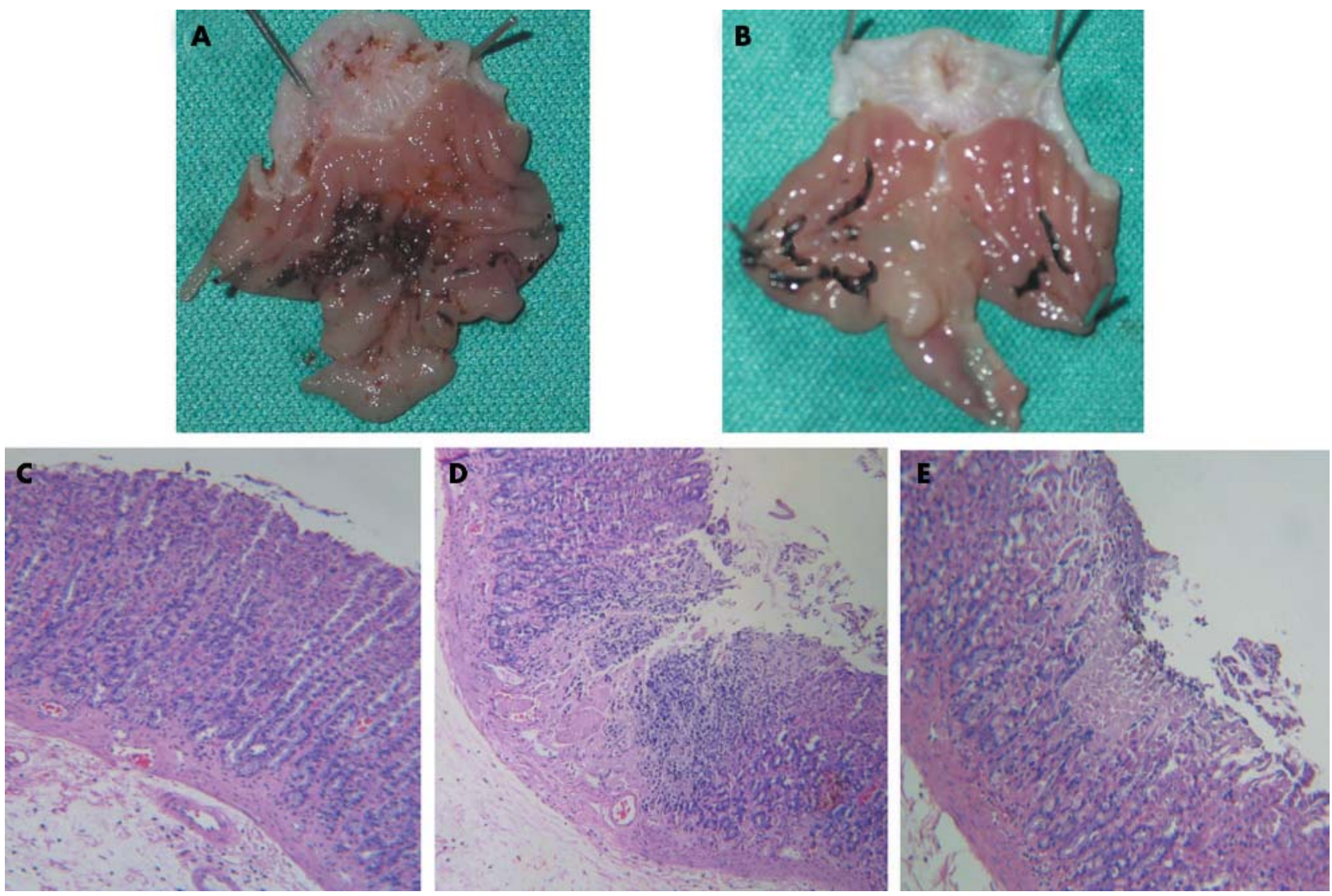

Figure 6 Apple polyphenol extracts (APE) prevented indomethacin induced injury to the rat gastric mucosa. Rats were pretreated with APE $10^{-4} \mathrm{M}$ in drinking water or vehicle (control) and then with indomethacin $35 \mathrm{mg} / \mathrm{kg}$ body weight subcutaneously and sacrificed three hours later. (A) Macroscopic appearance of gastric mucosa following indomethacin treatment in control vehicle treated rats. (B) Macroscopic appearance of the gastric mucosa following indomethacin treatment in APE treated rats. (C) Normal rat gastric mucosa. (D) Histological appearance of rat gastric mucosa following indomethacin treatment in control vehicle treated rats, showing extensive superficial epithelial damage and necrosis of gastric glands. (E) Histological appearance of rat gastric mucosa following indomethacin treatment in APE treated rats showing reduction in the extent of both superficial epithelial damage and necrotic lesions in the glandular area.

ROS in the stomach greatly contributes to the damaging effect exerted by a number of ulcerogens, ${ }^{2-4}$ we sought to investigate whether APE prevented oxidative stress induced injury to cultured gastric mucous cells in vitro, under conditions independent of acid secretion or systemic factors, including blood flow.

Our data indicate that APE counteract the damaging effect of X-XO generated ROS in gastric epithelial cells and that this protective effect seems to be mainly attributable to the major components of APE (that is, CAT and CA). This effect is
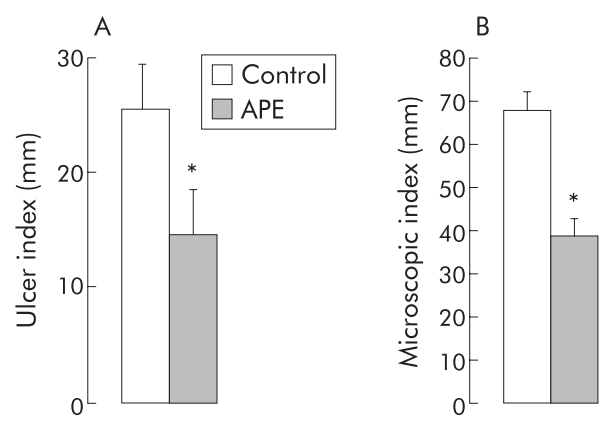

Figure 7 Quantitation of macroscopic (A) and microscopic (B) injury in control vehicle treated and APE treated rats, prior to indomethacin injection. Mean (SD) from eight rats per group. ${ }^{*} \mathrm{p}<0.05$ compared with controls. associated with permeation of gastric cells by apple phenolic compounds and seems to be due to their antioxidant activity. In fact, intracellular concentrations of apple phenolic compounds are significantly decreased by exposure of cells to $\mathrm{X}-\mathrm{XO}$, suggesting that these compounds are consumed by the cells to counteract the oxidative stress induced by X-X0. This hypothesis is further supported by the lack of an increase in the concentration of phenolic compounds in the culture medium of cells following treatment with $\mathrm{X}-\mathrm{XO}$, which rules out the possibility that the decrease in intracellular concentration of apple phenolics is due to increased leakage through damaged cell membranes. That APE significantly increased the intracellular antioxidant activity of gastric cells and prevented its decrease caused by exposure of cells to oxidative stress further supports the concept that the protective effect of APE is associated with the antioxidant activity of its phenolic compounds. Moreover, APE significantly prevented the increase in cellular MDA concentration (an index of lipid peroxidation) induced by X-XO. Because NSAID induced injury to the gastric mucosa is in part attributable to generation of ROS, ${ }^{3}{ }^{17}$ we evaluated whether APE were able to protect gastric cells in culture against damage brought about by indomethacin. Our data showed that pretreatment with APE significantly prevented indomethacin induced injury to human gastric epithelial cells.

We then sought to investigate whether APE might exert similar protective effects in vivo and found that chronic or acute treatment with APE significantly decreased the extent 
of macroscopic and microscopic injury induced by indomethacin to the rat gastric mucosa. These in vitro and in vivo observations further strengthen the concept that dietary antioxidants may exert potential beneficial effects in the prevention of exogenously induced gastric injury. In partial support of this concept, Singh and colleagues ${ }^{33}$ reported that melatonin and $\beta$-carotene were protective against indomethacin induced gastric injury in the rat and that this effect was mediated by scavenging of oxygen derived free radicals. Similarly, Alarcon de la Lastra and colleagues ${ }^{14}$ showed that extra virgin olive oil enriched diets prevented indomethacin induced gastric damage in rats. Also, several flavonoids have been reported to exert antiulcerogenic effects and this has been related to their ability to inhibit lipid peroxidation, to scavenge ROS, and/or to modulate leucocyte function..$^{34}$ Based on the results of our study one may therefore envision the use of apple phenolic compounds to prevent NSAIDs gastropathy.

The mechanism whereby dietary antioxidants protect the gastric mucosa against injury is not completely elucidated. Phenolic compounds have been shown to exert direct antioxidant effects acting as ROS scavengers, hydrogen donating compounds, singlet oxygen quenchers, and metal ion chelators. ${ }^{36}{ }^{37}$ Our study suggests that inhibition of lipid peroxidation together with the ability to increase intracellular antioxidant activity might be how APE exerts its protective effect. However, dietary antioxidants have also been demonstrated to significantly increase both glutathione peroxidase activity and total glutathione content in cultured rat hepatocytes ${ }^{38}$ and in gastric epithelium. ${ }^{39}$ This suggests that APE mediated cellular protective effect might also be due to enhancement of the glutathione antioxidant defence system. ${ }^{14}$ In agreement with this, we have previously shown that exogenous administration of reduced glutathione significantly prevented ethanol induced gastric mucosal injury in humans by preventing the ethanol induced decrease in the mucosal concentration of glutathione and its precursor cysteine. ${ }^{40}{ }^{41}$

Whether phenolic compounds exert exclusively antioxidant activity in cell systems is controversial. In fact, phenolic compounds have been found to be pro-oxidants and cytotoxic in a few studies. ${ }^{42}{ }^{43}$ It is possible that pro-oxidant effects on cultured cells by flavonoids and phenolic compounds derive from artefactual generation of oxidative stress. Phenolic compounds may indeed react with other components of the cell culture medium (such us metal ions) producing cytotoxic metabolites that have pro-oxidative effects. ${ }^{44}$ In our study, we tested cell viability of cells incubated with APE or its phenolic compounds and found no difference from control untreated cells.

$H$ pylori related gastric mucosal damage is associated with generation of ROS in the stomach. ${ }^{45}{ }^{46}$ Generation of ROS seems to play a crucial role in the multistep process of $H$ pylori related gastric carcinogenesis. ${ }^{47}{ }^{48}$ Based on the results of this study, we postulate that a diet rich in polyphenol compounds (from apple or other dietary source) due to their antioxidant activity might be suggested for the prevention of gastric adenocarcinoma. In partial support of this hypothesis, Serafini et al demonstrated that the intake of dietary antioxidant equivalents was inversely associated with the risk of gastric cancer. ${ }^{7}$

Considering that rats were consuming approximately $10 \mathrm{ml}$ of APE $10^{-4} \mathrm{M} /$ day, the amount of phenolics consumed each day by each rat was about $0.9 \mathrm{mg} / \mathrm{kg}$. This is comparable with the amount of phenolic compounds consumed by a person of $70 \mathrm{~kg}$ in weight eating two "Annurca" apples per day (that is, $0.80 \mathrm{mg} / \mathrm{kg}$ ).

Our data must be interpreted with caution as the cells used in this study were from an adenocarcinoma and the effects observed could potentially reflect the biology of a tumour cell more than that of normal non-transformed cells. However, we have previously compared MKN 28 cells with human gastric epithelial cells in primary culture and found comparable results with respect to their damaging and protective agents in vitro. ${ }^{20}$ Moreover, phenolic compounds have also been shown to exert a protective effect against oxidative stress in non-transformed rat hepatocytes in primary culture $^{38}$ as well as in in vivo studies..$^{33-35}$

In conclusion, (1) MKN 28 cells are a suitable in vitro system for screening vegetable compounds with antioxidative properties and for elucidating their mechanism of action; (2) APE prevent ROS induced injury to gastric epithelial cells by permeating cell membranes, increasing intracellular antioxidant activity, and inhibiting ROS dependent lipid peroxidation; and (3) APE significantly prevent indomethacin injury both in vitro and in vivo. These results suggest that a diet rich in apple antioxidants might exert a beneficial effect in the prevention of gastric diseases related to the generation of ROS.

\section{ACKNOWLEDGEMENTS}

We thank Mr Armando Coppola and Rosalia Ferracane, BS, for excellent technical support

\section{Authors' affiliations}

G Graziani, A Ritieni, F Morisco, V Fogliano, Dipartimento di Scienza degli Alimenti, Università di Napoli "Federico II" Parco Gussone, Ed 8480055 Portici (NA), Italy

G D'Argenio, Gastroenterologia, Universitò Federico II, Napoli, Italy C Tuccillo, C Loguercio, C D V Blanco, M Romano, Centro

Interuniversitario di Ricerche su Alimenti, Nutrizione ed Apparato Digerente (CIRANAD) and Dipartimento Medico Chirurgico di Internistica Clinica e Sperimentale, Cattedra di Gastroenterologia y Seconda Università di Napoli, Napoli, Italy

Conflict of interest: None declared.

\section{REFERENCES}

1 Hiraishi H, Terano A, Sugimoto T, et al. Protective role of intracellular superoxide dismutase against extracellular oxidants in cultured rat gastric cells. J Clin Invest 1994:93:331-8.

2 Mizui $T$, Sato $H$, Hirose $F$, et al. Effect of antiperoxidative drugs on gastric damage induced by ethanol in rats. Life Sci 1987;41:755-63.

3 Pihan G, Regillo C, Szabo S. Free radicals and lipid peroxidation in ethanolor aspirin-induced gastric mucosal injury. Dig Dis Sci 1987;32:1395-401.

4 Szelenyi I, Brune K. Possible role of oxygen free radicals in ethanol-induced gastric mucosal damage in rats. Dig Dis Sci 1988;33:865-71.

5 Oliveira CP, Kassab P, Lopasso FP, et al. Protective effect of ascorbic acid in experimental gastric cancer: reduction of oxidative stress. World J Gastroenterol 2003;9:446-8.

6 La Vecchia C, Tavani A. Fruit and vegetables, and human cancer. Eur J Cancer Prev 1998;7:3-8.

7 Serafini M, Bellocco R, Wolk A, et al. Total antioxidant potential of fruit and vegetables and risk of gastric cancer. Gastroenterology 2002;123:985-91.

8 Roukos DH, Paraskevaidis E, Agnantis NJ, et al. Fruits and vegetables: do they protect from gastric cancer? Gastroenterology 2003;124:2006-7.

9 Eberhardt M, Lee CY, Liu RH. Nutrition: Antioxidant of fresh apples. Nature 2000:405:903-4.

10 Le Marchand L, Murphy SP, Hankin JH, et al. Intake of flavonoids and lung cancer. J Natl Cancer Inst 2000;92:154-60.

11 Laughton MJ, Evans PJ, Moroney MA, et al. Inhibition of mammalian 5lipoxygenase and cyclo-oxygenase by flavonoids and phenolic dietary additives. Relationship to antioxidant activity and to iron ion-reducing ability. Biochem Pharmacol 1991;42:1673-81.

12 Ferro-Luzzi A, Ghiselli A. Protective aspects of the Mediterranean diet. Adv Exp Med Biol 1993;348:137-44.

13 Stavric B. Antimutagens and anticarcinogens in foods. Food Chem Toxicol 1994;32:79-90.

14 Alarcon de la Lastra C, Barranco MD, Martin MJ, et al. Extra-virgin olive oilenriched diets reduce indomethacin-induced gastric oxidative damage in rats. Dig Dis Sci 2002;47:2783-90.

15 Martin MJ, La-Casa C, Alarcon-de-la-Lastra C, et al. Anti-oxidant mechanisms involved in gastroprotective effects of quercetin. $Z$ Naturforsch (C) 1998;53:82-8.

16 Mirossay L, Kohut A, Mojzis J. Effect of malotilate on ethanol-induced gastric mucosal damage in capsaicin-pretreated rats. Physiol Res 1999;48:375-81. 
17 Takeuchi K, Ueshima K, Hironaka Y, et al. Oxygen free radicals and lipid peroxidation in the pathogenesis of gastric mucosal lesions induced by indomethacin in rats. Digestion 1991;49:175-84.

18 Ricci V, Manzo BA, Tuccillo C, et al. NSAIDs counteract H. pylori VacA toxin induced cell vacuolation in MKN 28 gastric mucosal cells. Am J Physiol 2002;283: G511-20.

19 Lommen A, Godejohann M, Venema D, et al. Application of directly coupled HPLC-NMR-MS to the identification and confirmation of quercetin glycosides and phloretin glycosides in apple peel. Anal Chem 2000;72:1793-7.

20 Romano M, Razandi M, Sekhon S, et al. Human cell line for study of damage to gastric epithelial cells in vitro. J Lab Clin Med 1988;111:430-40.

21 Hiraishi $\mathbf{H}$, Terano A, Ota S, et al. Oxygen metabolite-induced cytotoxicity to cultured rat gastric mucosal cells. Am J Physiol 1987;253:G40-8.

22 Hiraishi H, Terano A, Ota S, et al. Role of iron in reactive oxygen speciesmediated cytotoxicity to cultured rat gastric mycosal cells. Am J Physiol 1991;260:G556-63.

23 Hiraishi H, Terano A, Ota S, et al. Oxygen metabolites stimulate mucous glycoprotein secretion from cultured rat gastric mucous cells. Am J Physiol 1991;261:G662-8.

24 Buckley BJ, Tanswell AK, Freeman BA. Liposome-mediated augmentation of catalase in alveolar type II cells protects against $\mathrm{H} 2 \mathrm{O} 2$ injury. J Appl Physiol 1987:63:359-67.

25 Pellegrini N, Del Rio D, Colombi B, et al. Application of the 2,2'-azinobis(3ethylbenzothiazoline-6-sulfonic acid) radical cation assay to a flow injection system for the evaluation of antioxidant activity of some pure compounds and beverages. J Agric Food Chem 2003;51:260-4

26 Bergamo $P$, Fedele $E$, Balestrieri $M$, et al. Measurement of malondialdehyde levels in food by high-performance liquid chromatography with fluorometric detection. J Agric Food Chem 1998:46:2171-6.

27 Thirumalai CHR, Tseng CC, Tabata K, et al. Relationship between ornithine decarboxylase activity and gastric damage. Am J Physiol 1987;253:G1-6.

28 Schmidt KL, Henagan JM, Smith GS, et al. Prostaglandin cytoprotection against ethanol-induced gastric injury in the rat. Gastroenterology 1985:88:649-59.

29 Wang S-T. Analysis of complex survey data-a solution using SAS. Public Health 1998;4:273-5.

30 Schieber A, Keller P, Carle R. Determination of phenolic acids and flavonoids of apple and pear by high-performance liquid chromatography. J Chromatogr A 2001;910:265-73.

31 Tsao R, Yang R, Young CJ, et al. Polyphenolic profiles in eight apple cultivars using HPLC. J Agric Food Chem 2003;51:7347-53.

32 de Groot $\mathbf{H}$, Raven $\mathrm{U}$. Tissue injury by reactive oxygen species and the protective effects of flavonoids. Fundam Clin Pharmacol 1998;12:249-55.
33 Singh P, Bhargava VK, Garg SK. Effect of melatonin and beta-carotene on indomethacin induced gastric mucosal injury. Indian J Physiol Pharmacol 2002;46:229-34

34 Suzuki Y, Ishihara $M$, Segami T, et al. Anti-ulcer effects of antioxidants, quercetin, alpha-tocopherol, nifedipine and tetracycline in rats. Jpn J Pharmacol 1998;78:435-41.

35 Osakabe N, Sanbongi C, Yamagishi M, et al. Effects of polyphenol substances derived from Theobroma cacao on gastric mucosal lesion induced by ethanol. Biosci Biotechnol Biochem 1998:62:1535-8.

36 Rice-Evans CA, Miller NJ, Bolwell PG, et al. The relative antioxidant activities of plant-derived polyphenolic flavonoids. Free Radic Res 1995;22:375-83.

37 Mojzisova G, Petrasova D, Koprovicova J. Flavonoids with antioxidant action and their effect on human health. Slovakofarma Rev 1999;9:35-7.

38 Gebhardt R. Antioxidative and protective properties of extracts from leaves of the artichoke (Cynara scolymus L.) against hydroperoxide-induced oxidative stress in cultured rat hepatocytes. Toxicol Appl Pharmacol 1997; 144:279-86.

39 La Casa C, Villegas I, Alarcon de la Lastra C, et al. Evidence for protective and antioxidant properties of rutin, a natural flavone, against ethanol induced gastric lesions. J Ethnopharmacol 2000;71:45-53.

40 Loguercio C, Romano M, Di Sapio M, et al. Regional variations in total and nonprotein sulfhydryl compounds in the human gastric mucosa and effect of ethanol. Scand J Gastroenterol 1991;26:1042-8

41 Loguercio $C$, Taranto D, Beneduce F, et al. Glutathione prevents ethanolinduced gastric mucosal damage and depletion of sulfhydryl compounds in humans. Gut 1993;34:161-5.

42 Yang G, Liao J, Kim K, et al. Inhibition of growth and induction of apoptosis in human cancer cell lines by tea polyphenols. Carcinogenesis 1998;19:611-16.

43 Oshima H, Yoshie $\mathrm{Y}$, Auriol $\mathrm{S}$, et al. Antioxidant and pro-oxidant actions of flavonoids: effect on DNA damage induced by nitric oxide, peroxynitrite and nitroxyl anion. Free Radic Biol Med 1998;25:1057-65.

44 Lapidot T, Walker MD, Kanner J. Antioxidant and prooxidant effects of phenolics on pancreatic beta-cells in vitro. J Agric Food Chem 2002;50:7220-5.

45 Bagchi D, McGinn TR, Ye X, et al. Helicobacter pylori-induced oxidative stress and DNA damage in a primary culture of human gastric mucosal cells. Dig Dis Sci 2002;47:1405-12.

46 Nagata K, Yu Hidenori, Nishikawa A, et al. Helicobacter pylori generates superoxide radicals and modulates nitric oxide metabolism. J Biol Chem 1998;273:14071-3.

47 Tseng HH, Hsu PI, Chen HC, et al. Compartment theory in Helicobacter pyloriassociated gastric carcinogenesis. Anticancer Res 2003;23:3223-9.

48 Zarrilli R, Ricci V, Romano M. Molecular response of gastric epithelial cells to Helicobacter pylori-induced damage. Cell Microbiol 1999;1:93-9.

\section{EDITOR'S QUIZ: GI SNAPSHOT}

\section{Answer}

From question on page 178

Contrast enhanced computed tomography (fig lA) revealed small, multiple, spherical, nonenhancing hypodense lesions in both lobes of the liver, suggestive of metastases. The colonoscopy image (fig 1B) showed a caecal amoeboma. Histopathological examination of the colonic lesion revealed ulceration and necrosis. The lamina propria was heavily infiltrated with neutrophils, eosinophils, lymphocytes, and plasma cells. No dysplastic or malignant cells were seen. Granulomas or trophozoites of amoeba were absent even after PAS staining. However, serum entamoeba histolytica antibodies were markedly elevated. The patient responded well to metronidazole treatment for 21 days. Hepatic scan a year later revealed disappearance of the liver lesions.

Amoebomas are tumour-like lesions of the colonic wall and may be multiple. Metastatic hepatic abscesses occur when amoebae reach the liver in the portal vein from the gut. In the tropics, this condition may be indistinguishable from colonic cancer with malignant secondary deposits in the liver. Amoebic serology and colonic biopsies will clarify the diagnosis.

doi: $10.1136 /$ gut.2004.046102 